\title{
Colonial copyright: an early case of globalisation
}

by Michael Birnhack

$\mathrm{F}$ or British politicians and copyright lawyers during the 19th century, "colonial copyright" meant only the British Empire's related interests in its colonies. They hardly referred to the local cultural and legal interests in the colonies. Until recently, scholarly engagement with colonial copyright followed the Imperial path of the 19th century and was told almost exclusively from a British Imperial point of view. I reverse the perspective and provide an account as seen and understood from the colonized side.

Another aspect of this project is that while current studies in copyright history usually end with the enactment of the 1911 Copyright Act, the project examines the diffusion and reception of copyright law throughout the British Empire in the period after the enactment of the 1911 Copyright Act. Thus, this research explores the legal history of copyright law in the British Empire, during the first decades of the twentieth century. It tells a story about the use of law as a tool to secure British interests throughout the Empire, but also as a tool applied to promote progress and culture.

Colonial copyright is a legal and cultural category about the diffusion and transplanting of the legal field that regulates some of the main institutional aspects of culture. Colonial copyright occurred when a foreign power exported its own legal toolkit from home and applied it to territories and its peoples, previously unfamiliar with the idea of legal protection for creative works in the form today known as copyright.

In recent years, new voices have emerged in the history of copyright law. First studies that took a similar path to that taken here, focused on the English speaking, selfgoverning dominions, especially Canada. The current project provides the yet-untold story of copyright law in additional British territories, thus filling the gap in the developing academic discipline of copyright history.

The legal history of copyright law in Mandatory Palestine (1917-48) is the leading case study. Though Palestine was not a crown colony, it exemplified the basic tension between a foreign entity that brought with it its legal, political and cultural agenda and the local communities. Archival findings indicate that colonial copyright in Palestine was not a smooth one-way imposition of foreign law onto a local community, but rather a process of gradual reception of the law over time, which rolled out in different ways in the different local communities.

In a nutshell, copyright law was implemented in Palestine (first in 1920, by modifying a little-known Ottoman Authors' Rights Act and then again in 1924) due to a mix of British Imperial interests. The law was first ignored by the local communities, who either used alternative mechanisms of social norms or none at all; the law was finally set in motion by foreign players who entered the Palestinian field and successfully protected their interests; only then did the Jewish community begin to use the law, with the Arab community joining in only towards the end of the Mandate. The British government exercised the law in its own operations, but in a manner that reveals its differential treatment of the local communities.

This yet-untold history is located within an overarching framework, which is an explanatory model that I call colonial copyright. It builds on literature of legal transplants and of legal colonialism studies. It is supplemented by closely examining the regulated subject matter at stake, namely copyright.

The research and literature on legal transplants has developed over the past 40 years. Initially, it was a descriptive project of identifying cases and patterns of legal borrowing, in which one jurisdiction borrowed - or was subjected to - an entirely foreign legal system, or a set of rules in a particular legal field, or a specific law. A second phase in the transplant research was critical, querying the power relationships of the transplant. This critical approach also replaced the binary observation with a process-based view, realising that legal transplants do not just occur in a single legislative event, but rather are composed of several stages. The result is that instead of settling for noting a legal transplant, we should explore its different stages: who initiated it? Which purpose was it meant to serve? What was the legal mechanism of the transplant? Was it done with the consent of the recipient jurisdiction? How was it received? 
To this critical view, I add the paradigm of colonial law. While the Empire was interested in spreading the rule of law and had a self-image of a civilising mission, it was also to serve the homeland. The law was a tool to achieve both goals. There were many kinds of colonial law-making processes, ranging from a total imposition by London on the colony on the one end, to substantial local leeway to enact the law. The differences depended on the kind of colony (self-governing, crown colony, protectorate, and later - a League of Nations' mandate), on the specific legal field and many other factors. The outcome was that colonial law was often a complex amalgam of British principles with local principles, resulting in unique legal fusions.

A third element of the general model is that of the particular legal field at stake. We should search for the unique features of each legal field at stake, which interacts with the legal transplant and colonial law elements. In the case of copyright law, I identify three main features. One is the close kinship of copyright law with the 18 th century notion of progress. Copyright law was a tool to advance progress. It also fits neatly with the civilising mission mentioned above. A second feature is the content of the law: copyright law regulates some important aspects of the creative process. It determines which works are protected, to what extent, who owns them and what other can - and cannot - do with these works. As such, copyright law necessarily holds, albeit in a hidden way, some assumptions as to the creative process and its main actors: the authors. These observations are deeply rooted with the time, place and unique circumstances of the cultural setting in each place. The British imperial view was bound to differ from the perceptions of the creative process elsewhere.

A third relevant feature is the intangible nature of copyrighted works, which meant that they easily cross borders. Hence, there is the risk that works will be reproduced without authorisation in other countries, perhaps even re-entering the original market. Bearing in mind the critical view of legal transplants and the lessons of colonial law, we should look at the direction of this flow of works. It was not multi-directional, but rather the result of various political, economic and cultural factors.

Applying this to the case of Mandate Palestine indicates that by the early 20th century, the British interests in spreading copyright law have been crystallised. London wanted to spread the law throughout the Empire as much as it could, and in a uniform manner, as much as possible. To this end, it kept a close eye on the legislative process. Nevertheless, a local initiative of the Mandatory government in Jerusalem predated this intervention, with the enactment of a local Copyright Ordinance (1920). It was the fourth piece of legislation by the newly established civil administration, quite an unusual preference. A full-scale copyright regime was imposed in 1924, unifying it with the law elsewhere in the Empire.
But there was a substantial difference between the image of the author as assumed and imagined by the law and the local perception of the author's image. Focusing on the Hebrew, Jewish community, I explore the local image. It was of a romantic figure, but one whose identity is defined by membership of a collective; the collective often had a socialist touch, and above all, the Hebrew author was a national character, a Zionist. Nationality was the most important issue of the day, as the new movement was (re)inventing itself as a national people (rather than just a religious group). Nationality was absent from the foreign law. There was a gap between the colonial copyright and the local needs and views. For some time during the 1920s, the law was simply irrelevant for the local community.

In the absence of a relevant law, the local Hebrew community developed an alternative scheme of private ordering, composed of literary norms, requiring high levels of originality; commercial norms, about keeping contracts; and finally, a set of social norms, that served as an enforcement mechanism. The latter were mostly in the form of public shaming. When an author was dissatisfied with the publisher's attitude or misbehaviour, the author published a notice in a literary journal. This practice was applied for several years.

Finally, in the 1930s, with the advancement of technologies that enabled listening to recorded music, with the entrance of talking movies in Palestine and then radio broadcasting, copyright law was finally set in motion. Interestingly, and similar to other places, the first to use the law were foreign parties, namely the European performing rights societies.

The case study and the broader frame of colonial copyright are not just a historical tale. They are highly relevant for contemporary debates, where we often see that copyright law is imposed through quite aggressive international channels such as the TRIPS Agreement and a network of bilateral free trade agreements, on unwilling countries. The result might be a legal transplant, but the appearance of a statute in the law books does not in itself assure that it will be used in practice and how. We are more likely to end up with various combinations of the global and the local, or in another word, glocal. Colonial copyright is an early case of such a process.

\section{Michael Birnhack}

\section{Professor of Law, Tel Aviv University, Israel; Fellow, IALS}

- This seminar was presented by the author this at the IALS on May 17, discussing his current research project. The author wishes to thank the Institute of Advanced Legal Studies and the Cegla Centre for interdisciplinary research of the law for their support. 